\title{
Correction to: Isothermal Phase Transformations in a Low Carbon Steel During Single and Two-Step Partitioning
}

\author{
F.M. CASTRO CERDA, E.I. HERNÁNDEZ, T. ROS-YANEZ, and R.H. PETROV
}

https://doi.org/10.1007/s11661-021-06201-z

(C) The Minerals, Metals \& Materials Society and ASM International 2021

\section{Correction to: Metallurgical and Materials Transactions A, Volume 51A, April 2020 \\ https://doi.org/10.1007/s11661-020-05643-1}

THE authors wish to amend a misinterpretation of the constrained carbon equilibrium accompanied by carbide precipitation (CCE $\theta$ ) model by Toji et al. (Y. Toji, G. Miyamoto, and D. Raabe: Acta Mater., 2015, vol. 86, pp. 137-47). The original model established that the equilibrium between tempered martensite and austenite is determined solely by equating the carbon potentials in martensite, austenite and carbide phases. Our interpretation was based on the mass balance of carbon between the three phases, considering that carbide precipitation in martensite occurs under paraequilibrium conditions. In the corrected version of the paper, the calculations made under equal carbon potentials in the three phases was called CCE $\theta$, as in the original paper by Toji et al. The predictions under a mass balance of carbon were denoted as BCE $\theta$ (balanced carbon equilibrium accompanied by carbide precipitation). The prediction of carbon content in austenite is therefore different in both approaches.

The original online version of the article has been corrected.

Publisher's Note Springer Nature remains neutral with regard to jurisdictional claims in published maps and institutional affiliations.

F.M. CASTRO CERDA is with the Department of Metallurgy, University of Santiago de Chile, Alameda 3363, 9170022 Estación Central, Santiago, Chile and the Department of Materials Science and Engineering, Delft University of Technology, Mekelweg 2, 2628 CD Delft, The Netherlands. Contact e-mail: felipe.castro@usach.cl E.I. HERNÁNDEZ is with the Department of Metallurgy, University of Santiago de Chile and the Department of Electromechanical Systems and Materials, Research group Materials Science and Technology, Ghent University, Tech Lane Science Park Campus A 46, Gent, Belgium. T. ROS-YANEZ is with ArcelorMittal Global R\&D, $3001 \mathrm{E}$. Columbus Dr., East Chicago, IN 46312. R.H. PETROV is with the Department of Electromechanical Systems and Materials, Research group Materials Science and Technology, Ghent University and the Department of Materials Science and Engineering, Delft University of Technology.

The original article can be found online at https://doi.org/10.1007/ s11661-020-05643-1.

Article published online April 9, 2021 